\title{
Novel Magnesium Elektron21-AlN Nanocomposites Produced by Ultrasound-Assisted Casting; Microstructure, Thermal and Electrical Conductivity
}

\author{
Abdollah Saboori * (D), Elisa Padovano, Matteo Pavese and Claudio Badini \\ Department of Applied Science and Technology (DISAT), Politecnico di Torino, Corso Duca Degli Abruzzi 24, \\ 10129 Torino, Italy; Elisa.padovano@polito.it (E.P.); Matteo.pavese@polito.it (M.P.); \\ Claudio.badini@polito.it (C.B.) \\ * Correspondence: Abdollah.saboori@polito.it; Tel.: +39-011-090-4762
}

Received: 29 November 2017; Accepted: 24 December 2017; Published: 26 December 2017

\begin{abstract}
In the current work, a novel magnesium alloy Elektron21 reinforced by ceramic AlN nanoparticles were produced by an ultrasound-assisted casting. The fabricated nanocomposites were investigated to evaluate their microstructure, hardness, physical, thermal and electrical conductivity. The microstructural evolutions show that a uniform dispersion of the ceramic particles within the matrix can be achieved by employing the ultrasound-assisted stirring. However, some nanoparticles were found to be pushed by the solidification front. According to the Vickers hardness results, the addition of AlN nanoparticles results in a slight improvement of the mechanical properties of the nanocomposites. What is surprising is that both electrical and thermal conductivity of the nanocomposite were improved significantly as a consequence of AlN addition. This improvement in the conductivity characteristics of the nanocomposite is mainly corresponding to the structural effect of nanoparticles within the matrix.
\end{abstract}

Keywords: nanocomposite; Elektron21; thermal conductivity; electrical conductivity

\section{Introduction}

One of the solutions for reduction of fuel consumption and greenhouse emissions in the automotive and aeronautic industries is light weighting that can address the present and future challenges [1-3]. Among all the metals, magnesium could gain widespread attention in these industries owing to its strength/ductility ratio and low density [4,5]. Nowadays, Mg alloys with elements of rare earth (RE), in particular, Elektron21 (El21), have been introduced in the aerospace applications because of its improved corrosion resistance and production costs. However, not all applications allow working with El21 and also improvement of mechanical properties of complex as-cast parts by heat treatment is most of the time limited or impossible [6]. Good castability, fine grains and clean microstructure are the main factors for designing a lightweight castable alloy that can be full filled with the homogeneous addition of nanoparticles in the molten alloy. Besides the mechanical strength at high temperatures, thermal properties such as specific heat capacity and thermal conductivity are very important for high-temperature applications $[4,7]$. Thus, it is necessary for the metallurgical industries to determine these properties precisely. So far, however, there has been little data about the thermal properties of El21 and no data regarding the El21 nanocomposites.

The aim of this paper is to explore the effect of ultrasound-assisted stirring on the dispersion of the AlN nanoparticles, to investigate the influence of nanoparticles on the Vickers hardness, electrical and thermal conductivity of the novel El21-AlN nanocomposites for the first time. 


\section{Materials and Methods}

Commercial El21 (composition in wt.\%: Mg-2.8Nd-1.2Gd-0.4Zr-0.3Zn was melted and kept at $720{ }^{\circ} \mathrm{C}$ for $1 \mathrm{~h}$ and then poured into a preheated cylindrical mould. Thereafter, the spherical AlN nanoparticles (20-30 nm) with 20\% pure Al as an impurity were added into the melt, stirred and power ultrasound was additionally applied for $6 \mathrm{~min}$ at $0.3 \mathrm{~kW}$ under a flux of protective gas. After sonication the mould was could down in a water bath.

Hardness measurements were undertaken with a load of $5 \mathrm{~kg}$ and the dwell time was 15 s. A Field-Emission Scanning Electron Microscope (FESEM; Merlin-Zeiss; Munich, Germany) equipped with an energy-dispersive X-ray spectrometer (EDS; Munich, Germany) was employed for microstructural evaluations. Laser-flash method was used to measure the thermal diffusivity, by using a FLASHLINETM apparatus (Anter corporations, Pittsburgh, PA, USA). The electrical conductivity of El21 and its nanocomposites was measured by means of an eddy current electrical conductivity meter. All the results of electrical conductivity, thermal conductivity and Vickers hardness are taken from an average of three measurements.

\section{Results and Discussion}

The as-cast El21 alloy which is shown in Figure 1a is characterized by $\alpha-\mathrm{Mg}$ solid solution and $\mathrm{Mg}_{3}(\mathrm{Nd}, \mathrm{Gd})$ eutectic phase on the grain boundaries. Indeed, $\mathrm{Mg}_{3}(\mathrm{Nd}, \mathrm{Gd})$ eutectic phase is a modification of $\mathrm{Mg}_{3} \mathrm{Nd}$ phase where the $\mathrm{Nd}$ is partially replaced by $\mathrm{Gd}$ without modifying the crystal structure. Since the difference between the atomic radii of $\mathrm{Nd}$ and $\mathrm{Gd}$ is negligible this substitution does not destroy the crystal structure [7]. The EDS analysis of the $\mathrm{Mg}_{3}(\mathrm{Nd}, \mathrm{Gd})$ eutectic phase confirms the simultaneous presence of $\mathrm{Gd}$ and $\mathrm{Nd}$ in the eutectic phase (Figure 1c,d). The average grain measurement which is undertaken by image analysis software has shown that the addition of AlN nanoparticles results in a slight gain refinement. Indeed, the average grain size El21 which is $80.1 \mu \mathrm{m}$ is reduced to 74.1 and $72.8 \mu \mathrm{m}$ for El21-1\%AlN and El21-2\%AlN, respectively. As can be seen in Figure $1 b$, which is the microstructure of El21-2\%AlN despite the presence of some agglomerates, the dispersion of AlN nanoparticles seems to be rather homogeneous.
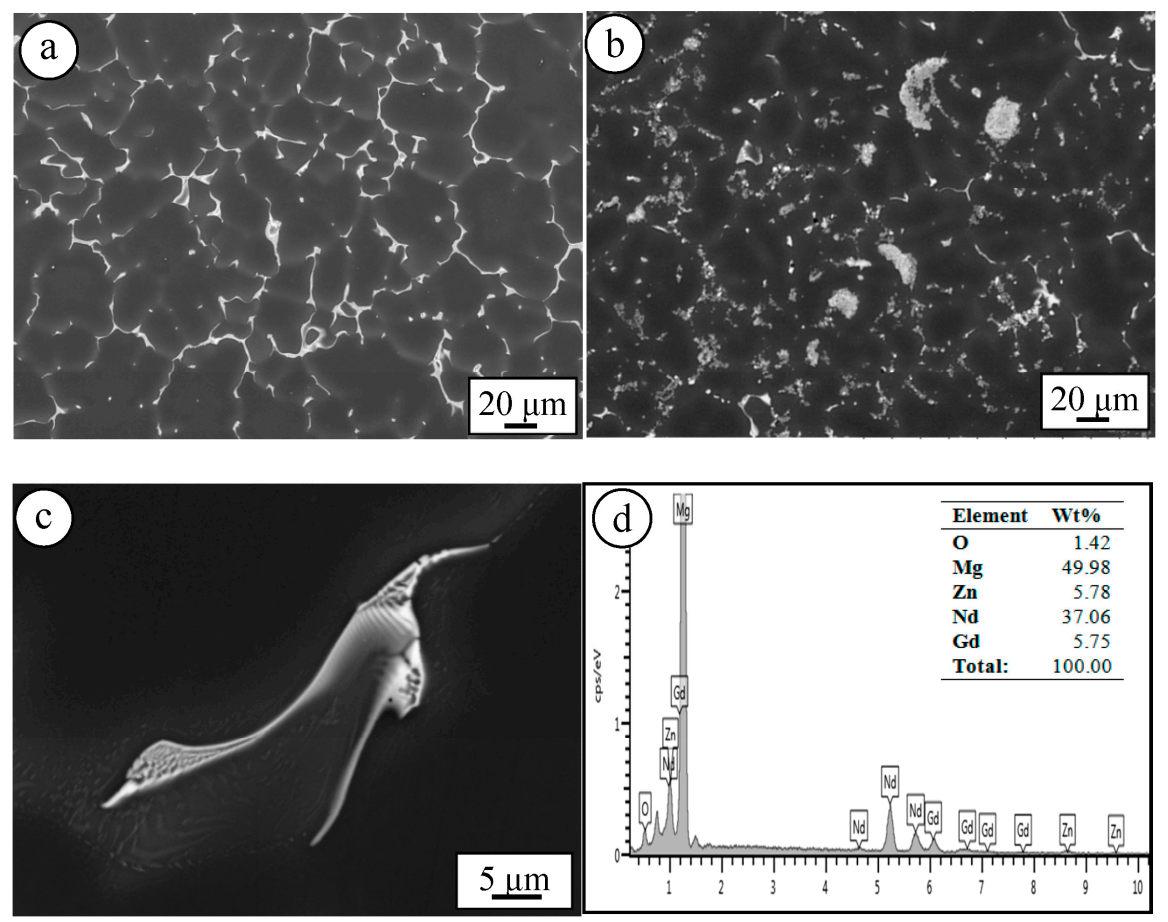

Figure 1. Microstructure of as-cast (a) El21; (b) El21-2\%AlN; (c,d) El21 and its corresponding EDS. 
X-ray diffraction patterns of as-cast EL21 which is shown in Figure 2a identified the main peaks corresponding to $\mathrm{Mg}$ (the matrix phase). Moreover, the peaks related to the $\mathrm{Mg}_{3} R E$ phase as the main intermetallic phase were detected. Surprisingly, in as-cast condition, the El21 alloy already displays a high density of intermetallic precipitates. However, in the X-ray patterns of as-cast El-1\%AlN and as-cast El-2\%AlN nanocomposite which are shown in Figure $2 \mathrm{~b}, \mathrm{c}$ the main peaks corresponding to $\mathrm{Al}_{2} \mathrm{Nd}$ were detected beside the other peaks ( $\mathrm{Mg}$ and $\mathrm{Mg}_{3} \mathrm{RE}$ ). This means that part of $\mathrm{Al}$ introduced as an impurity with $\mathrm{AlN}$ particles reacts with $\mathrm{Nd}$ and forms $\mathrm{Al}_{2} \mathrm{Nd}$.
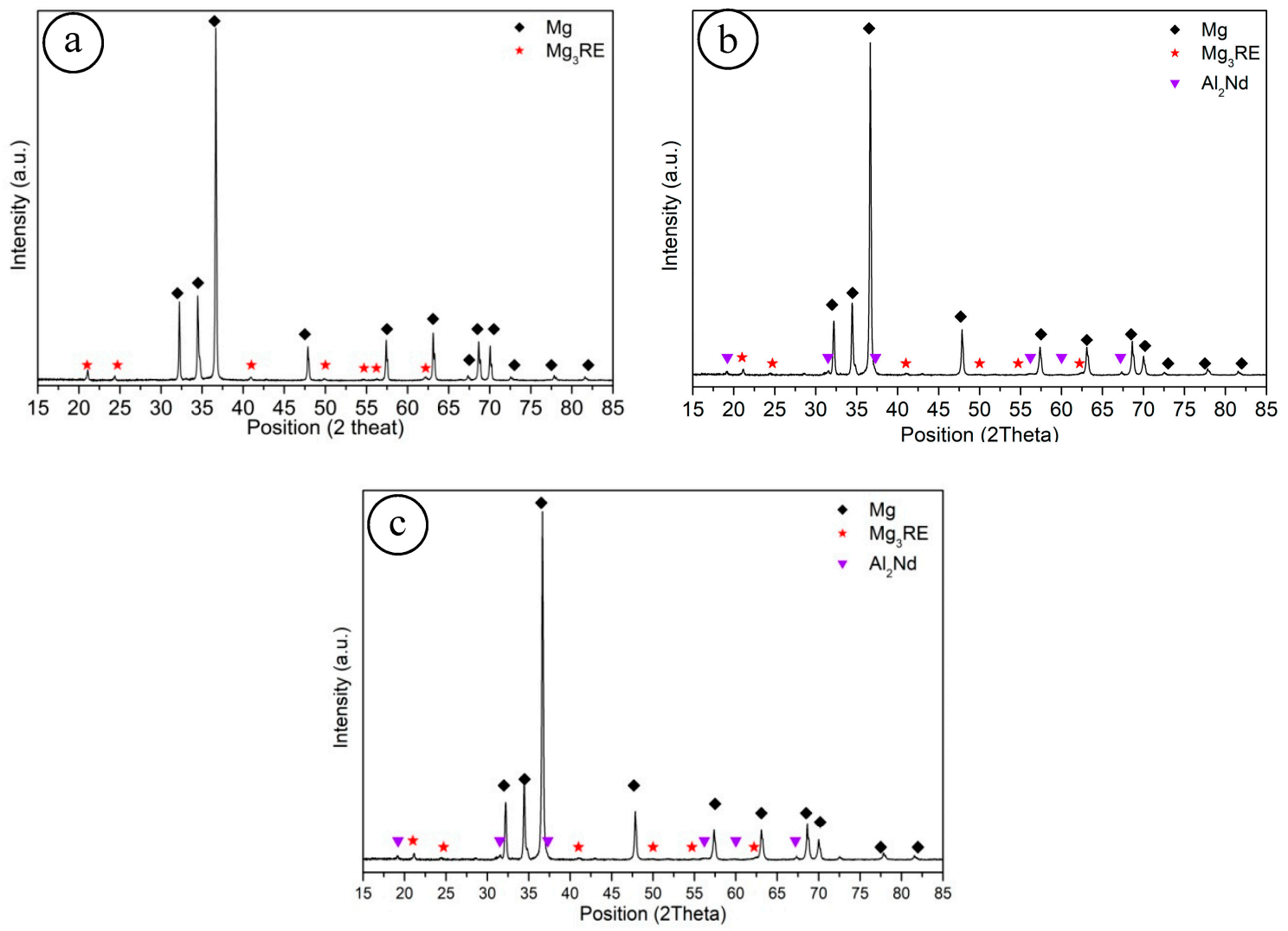

Figure 2. X-ray diffraction patterns of (a) El21; (b) El21-1\%AlN; (c) El21-2\%AlN in as-cast condition.

Temperature dependence of the Thermal conductivity of El21, El21-1\%AlN and El21-2\%AlN in as-cast condition is shown in Figure 3. In these novel El21-AlN nanocomposites, the thermal conductivity of the nanocomposites was improved significantly as a function of AlN content. Indeed, this noticeable improvement in the nanocomposites can be related to the two main phenomena. The first reason is related to the microstructural effect of AlN nanoparticles which contained some Al as an impurity. Generally speaking, $\mathrm{Mg}$ is well-known because of its high thermal conductivity and high efficiency of heat dissipation [8]. It is found that in multicomponent alloys the solute elements in the alloy act as scattering centers of phonon contribution to thermal transfer [9]. In this work, as a matter of fact, as shown by XRD patterns $\mathrm{Al}$ particles which were inserted in the nanocomposites reacted with $\mathrm{Nd}$ which is a solute element and forms $\mathrm{Al}_{2} \mathrm{Nd}$. It implies that this reaction results in the reduction of scattering point and consequently improvement of the thermal conductivity of the nanocomposite with respect to the El21. Indeed, these findings are in line with the previous works $[7,9]$. 


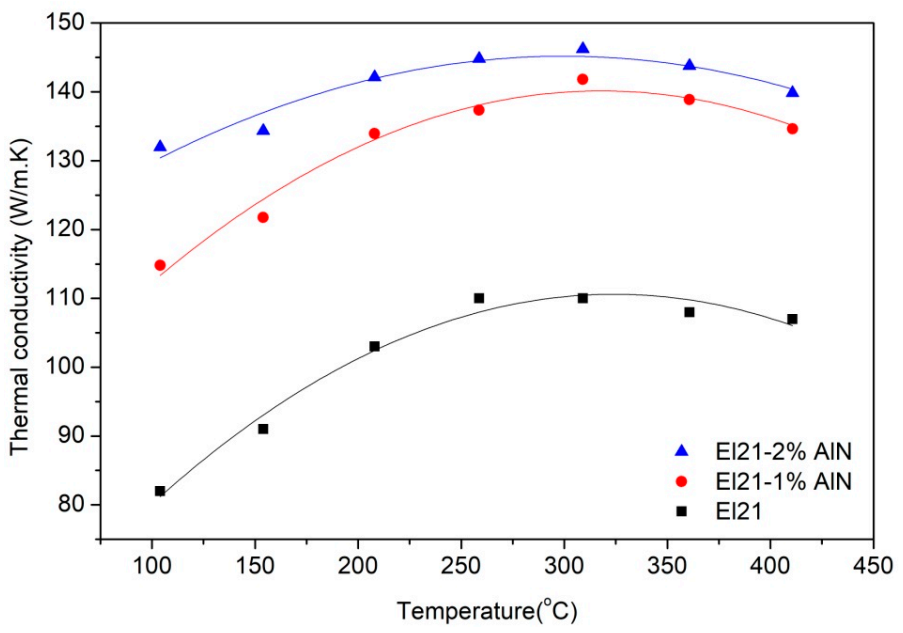

Figure 3. Temperature dependence of the Thermal conductivity of El21, El21-1\%AlN and El21-2\%AlN in as-cast condition.

Kielbus et al. have investigated the effect of solute elements on the thermal conductivity of $\mathrm{Mg}$ [7]. For this reason, they compared the thermal conductivity of EL21 and WE54 (Mg-Y-Nd) before and after the solution treatment. In both cases, the thermal conductivity of alloys was very low because of their higher solute element content in the $\alpha-\mathrm{Mg}$ matrix. In addition, they have shown that the thermal conductivity of El21 was higher than WE54 because of the lower amount of elements and lower dissolubility of $\mathrm{Gd}$ (in comparison with $\mathrm{Gd}$ ) in solid solution. The second reason for thermal conductivity improvement could be as a consequence of the reaction bonding between the nanoparticle and the matrix that results in the thermal conductivity improvements. Indeed, it is reported that $\mathrm{Zr}$ atoms which are a parent in the matrix can be incorporated in the AlN surface and accordingly $\mathrm{ZrN}$ forms and some $\mathrm{Al}$ released [10]. This released $\mathrm{Al}$ can also consume the $\mathrm{Nd}$ element a solute atom and form $\mathrm{Al}_{2} \mathrm{Nd}$ (as shown earlier by $\mathrm{XRD}$ ). These Consecutive reactions improve the thermal conductivity of El21-AlN nanocomposites through two mechanisms; (i) formation a reaction bonding between the matrix and reinforcement and (ii) consumption of a solute element which has a noticeable effect on thermal conductivity of El21 alloy.

Table 1 shows the Vickers hardness and electrical conductivity results of El21 and El21-AlN nanocomposites. As can be seen in this table, the Vickers hardness of El21-AlN nanocomposites improved slightly. This slight improvement in Vickers hardness of nanocomposites shows that the incorporation of AlN nanoparticles which does not result in the grain refinement, cannot improve the Vickers hardness of nanocomposites. Nonetheless, this slight increase in the Vickers hardness of nanocomposite could be as a consequence of the incorporation of AlN nanoparticles. As a matter of fact, the nanoparticles within the matrix could hinder the dislocation motions and accordingly improves the hardness of the composite. The electrical conductivity results of El21 and its nanocomposites at the ambient temperature is presented in Table 1.

It is evident that as same as the thermal conductivity of nanocomposites, their electrical conductivity is increased noticeably as a consequence of decreasing the scattering points of free electrons within the matrix through the solute element consuming. As discussed earlier some pure $\mathrm{Al}$ particles is introduced into the El21 and reacts with $\mathrm{Nd}$ which is a solute atoms and consequently reduced its content in solid solution and leads to the electrical conductivity improvement. 
Table 1. Vickers hardness and electrical conductivity of El21 and its composites at ambient temperature.

\begin{tabular}{|c|c|c|c|}
\hline Material & EL21 & El21-1\%AlN & El21-2\%AlN \\
\hline Vickers hardness $\left(\mathrm{HV}_{5}\right)$ & $55 \pm 2.1$ & $60 \pm 1.2$ & $62 \pm 1.1$ \\
\hline Electrical conductivity at room temeprature $(\mathrm{S} / \mathrm{m})$ & $1.34 \times 10^{7}$ & $1.86 \times 10^{7}$ & $2.06 \times 10^{7}$ \\
\hline
\end{tabular}

\section{Conclusions}

Magnesium-based nanocomposites consist of Elektron21 as a matrix and AlN nanoparticles as reinforcement were successfully produced by ultrasound assisted casting technique. Microstructural evaluations show that the AIN nanoparticles were dispersed uniformly within the matrix. However, some AlN agglomeration has been detected after casting as a consequence of particle pushing during the solidification of nanocomposites. Moreover, it is found that the addition of AlN nanoparticles did results in a slight reduction in grain size and a slight increase in hardness with the addition of nanoparticles. The thermal and electrical conductivity results of nanocomposites show a significant improvement with respect to the El21 alloy. The XRD analysis confirms that the pure aluminium which is incorporated within the molten alloy as an impurity together with AlN nanoparticles and also released after the reaction between the $\mathrm{Zr}$ and $\mathrm{AlN}$ reacts with $\mathrm{Nd}$ and creates $\mathrm{Al}_{2} \mathrm{Nd}_{\text {phase. }}$ This reaction between $\mathrm{Al}$ and $\mathrm{Nd}$ leads to the consumption of $\mathrm{Nd}$ which is an alloying element and reduce its amount in the solid solution.

Acknowledgments: This work was supported by the EXOMET Project, which is co-funded by the European Commission in the 7th Framework Programme (contractFP7-NMP3-LA-2012-280421), by the European Space Agency and by the individual partner organizations.

Author Contributions: In this work which was carried out in the 7th framework programme, the design of experiment and experimental phase have been carried out by Abdollah Saboori and Elisa Padovano. Matteo Pavese and Claudio Badini have taken part in analyzing the data and technical revising the manuscript.

Conflicts of Interest: The authors declare no conflict of interest.

\section{References}

1. Mounib, M. Electron Microscopy Characterization of Magnesium based Composites and Aluminium Master Alloys Processed under the Influence of External Fields; Université De Rouen: Mont-Saint-Aignan, France, 2015.

2. Saboori, A.; Novara, C.; Pavese, M.; Badini, C.; Giorgis, F.; Fino, P. An Investigation on the Sinterability and the Compaction Behavior of Aluminum/Graphene Nanoplatelets (GNPs) Prepared by Powder Metallurgy. J. Mater. Eng. Perform. 2017, 26, 993-999. [CrossRef]

3. Saboori, A.; Pavese, M.; Badini, C.; Fino, P. Microstructure and thermal conductivity of Al-Graphene composites fabricated by powder metallurgy and hot rolling techniques. Acta Metall. Sin. (Engl. Lett.) 2017, 30, 675-687. [CrossRef]

4. Dieringa, H. Properties of magnesium alloys reinforced with nanoparticles and carbon nanotubes: A review. J. Mater. Sci. 2011, 46, 289-306. [CrossRef]

5. Lyon, P.; Syed, I.; Heaney, S. Elektron 21-An aerospace magnesium alloy for sand cast and investment cast applications. Adv. Eng. Mater. 2007, 9, 793-798. [CrossRef]

6. Saboori, A.; Padovano, E.; Pavese, M.; Dieringa, H.; Badini, C. Effect of solution treatment on precipitation behaviors, age hardening response and creep properties of elektron 21 alloy reinforced by AlN nanoparticles. Materials 2017, 10, 1380. [CrossRef] [PubMed]

7. Kielbus, A.; Rzychon, T.; Moskal, G. The influence of heat treatment parameters on the thermal diffusivity of WE54 and elektron 21 magnesium alloys. Defect Diffus. Forum 2011, 312-315, 489-494. [CrossRef]

8. Zhang, X.; Wang, H.; Liao, L.; Teng, X.; Ma, N. The mechanical properties of magnesium matrix composites reinforced with $\left(\mathrm{TiB}_{2}+\mathrm{TiC}\right)$ ceramic particulates. Mater. Lett. 2005, 59, 2105-2109. [CrossRef] 
9. Zhao, S.; Zheng, Z.; Huang, Z.; Dong, S.; Luo, P.; Zhang, Z.; Wang, Y. Cu matrix composites reinforced with aligned carbon nanotubes: Mechanical, electrical and thermal properties. Mater. Sci. Eng. A 2016, 675, 82-91. [CrossRef]

10. López-pérez, W.; González-hernández, R.; Arbey, J.; Rodríguez, M. Zirconium adsorption and incorporation on a reconstructed Al- $\mathrm{T}_{4} \mathrm{AlN}(0001)$ surface. J. Phys. Chem. Solids 2013, 74, 1387-1391. [CrossRef] 